\title{
A Note on the Pricing of Liquidity in Stock Returns
}

\section{Nawazish Mirza*}

\section{Introduction}

Keynes (1930) proposed that an asset is more liquid than another "if it is more certainly realisable at short notice without loss" (vol. II, p. 67). This definition suggests that the liquidity of an asset is twofold. First, an asset should have a market that can readily absorb the sale, and second, do so without risk to its final value. This suggests that investors should be rewarded for both the level of liquidity and liquidity risk. The standard form of asset pricing models assumes financial markets to be perfectly liquid. In a perfectly liquid market, there are no arbitrage possibilities. Therefore, the under traditional asset pricing approach, all assets that have similar expected cash flows must have the same price. This phenomenon of frictionless markets ignores the impact of liquidity of financial assets on their respective prices and consequently on returns. The relation between liquidity and expected returns has been statistically observed and explains certain market anomalies such as the small firm effect, equity premium, and risk-free rate puzzle.

In a market with frictions, one source of illiquidity is transaction costs, which are ignored in the traditional asset pricing framework. Such costs might include brokerage fees, order processing costs, etc. Whenever a security is traded, the buyer and seller incur transaction costs. Moreover, the buyer will bear additional transaction costs whenever the security is further sold in the market. Apart from transaction costs, other sources of liquidity could be demand pressure and inventory risk. Demand pressure can be created in a market where buyers are not available, and to liquidate the position, the seller might have to settle for a much lower price. The factor of demand pressure might be worsened in the presence of circuit breakers in a continuously bearish market. If the prices hit the lower circuit, sellers will not be able to lay off their positions and this phenomenon will continue if, on the following days, prices continue to open on their lower

* PhD Candidate at University of Paris Dauphine, Assistant Professor (on leave) Finance, Center for Research in Economics and Business, Lahore School of Economics. 
circuits. ${ }^{1}$ In the presence of such demand pressure, buyers will enter and transact at a much lower price, causing a significant loss for sellers. However, buyers who buy in anticipation of an increase in prices will later be exposed to the risk of price changes while holding the asset in inventory. The buyer must be compensated for this risk-a compensation that imposes a cost on the seller in the form of a lower price.

Insider information can also be a source of illiquidity and can cause market friction. Buyers might fear that sellers have insider information (negative profits to be declared) and sellers might fear the opposite (high profits). Thus, trading with an informed counter party will end up with a loss. In over-the-counter (OTC) markets, another source of illiquidity can occur when it becomes difficult to locate a counter party who is willing to trade a particular security or a large quantity of a given security. This search friction is more likely to exist in OTC markets because of the nonavailability of a central marketplace. A searching trader will incur financing costs or opportunity costs as long as his trade is delayed and may need to settle the deal at a low price. Alternatively, the trader might choose to trade quickly by bearing the illiquidity cost.

Illiquidity costs should affect security prices because investors incorporate them in their required rate of return. Moreover, since liquidity varies over time, every risk-averse investor may require compensation for being exposed to liquidity risk. This compensation is more relevant to countering inventory risk. The effects of liquidity on asset prices are important. Investors must incorporate them in designing their investment strategies. The impact of liquidity, if incorporated into the required rate of return for investors, will ultimately affect corporations' cost of capital and hence the allocation of the economy's real resources.

\subsection{Liquidity and Asset Pricing}

Several asset pricing models have been introduced in the literature to explain how investors measure risk and value risky assets. ${ }^{2}$ At the forefront are the capital asset pricing model (CAPM) and subsequent extensions of the CAPM, as well as the arbitrage pricing theory (APT).

\footnotetext{
${ }^{1}$ This phenomenon was observed in the Pakistan stock market (Karachi Stock Exchange) in March 2005, when prices continuously opened at lower circuits for a week. Consequently, sellers were unable to square their positions.

${ }^{2}$ For more on asset pricing models and their origin, see Bachelier (1900), Markowitz (1952), Tobin (1958), Sharpe (1964), Mossin (1966), Litner (1965), Ross (1976), and Fama and French (1992).
} 
According to these models, expected returns can be predicted given specific related variables. Empirical tests of the CAPM use the risk of the market as measured by beta-a measure of the relative variability of a security's return compared to the variability of the entire market's return. The CAPM uses the beta of a security in conjunction with the risk premium on the market to account for the expected risk premium on a specific security, where it attempts to account for the market's perception of risk and return. However, critics of the CAPM point out that beta does not accurately capture the risk that investors face. In general, studies have shown that the beta of a security is an incomplete measure of risk. For example, Hansen and Jagannathan (1997) show that there are portfolios comprising stocks with small capitalization that earn higher returns on average than those predicted by the CAPM. This implies that there may be something missing from the model, namely some component of risk. Due to such shortcomings, extensions of the CAPM and APT have evolved to bridge this gap and try to account for the missing risk. Most recent models either remove beta from the model and replace it with a more complete proxy of risk faced by investors or add other variables that may aid beta in capturing the true risk an investor encounters.

Recent studies have tried to identify factors that accurately predict returns. Studies by Banz (1981), Rosenberg, Reid, and Lanstein (1985), and Fama and French (1992) show that factors other than a stock's beta can predict returns. One such factor is liquidity, which is the risk that investors face for not being able to readily transfer ownership of a security. Therefore, the returns earned on the small capitalization stock portfolio of Hansen and Jagannathan (1997) above that of the CAPM may be explained by a missing risk measure. In recent years, increasing attention has been given to liquidity as an explanatory factor of asset pricing (Chordia, Roll, and Subrahmanyam, 2002).

As mentioned earlier, standard asset pricing models (CAPM, APT, etc.) assume markets to be frictionless, where securities can be traded without transaction costs. The fair value of a security is the present value of all its future cash flows. This rationale implies that every security with a similar stream of cash flows must yield the same price in the market. Surprisingly, in the real world, securities with similar cash flows can yield a different price. This price differential is based on investors' expectations, which are different from their equilibrium state. This deviation can be attributed to various factors, including the liquidity or illiquidity of a particular security. Although intrinsic value logic prevails, in long-term securities, an important consideration for investors is that ownership of the 
securities will change hands over time. Therefore, their beliefs concerning the potential of future trading will affect investors' current demand for these securities. The future trading potential depends solely on the counterparty's preferences concerning that security. Ultimately, these factors are reflected in investors' required rate of return, causing the deviation from the equilibrium returns of standard asset pricing.

Equilibrium-based standard asset pricing models assume investors to be price takers. This assumption might not hold in certain circumstances and therefore advocates of liquidity-based asset pricing relax this assumption. If trading activity is going to affect the price level of a security, investors must take this into account. If an investor is going to place a significantly large "buy" order, prices in the market will ultimately increase. This effect must be incorporated in the pricing by the investor. Moreover, liquidity-based asset pricing assumes that not necessarily all investors have the same information. The existence of insider trading will affect stock prices in markets with friction. Apart from insider information about the fundamentals of a security, some market participants might have private information about the order flow. Brokers acting for hedge funds might know that the fund needs to liquidate a large position that will result in a decline in prices. Brokers can short sell at this point and buy later at lower price levels.

The importance of liquidity comes from investors' desire to reap greater rewards for the larger risk they incur. Investors require a certain level of liquidity to be able to move in and out of securities without being subject to losses. Given this desire, investors require a risk premium for securities that do not meet their liquidity needs. Specifically, liquidity and asset returns have an inverse relationship, where investors are willing to accept a lower return from securities with a higher level of liquidity.

\subsection{Measures of Liquidity}

One problem in empirical literature is determining the measure of liquidity, as there is hardly any single measure that can capture all its aspects. Moreover, these measures are sometimes constrained by their nonavailability. The data required is high-frequency, which is not normally available for every security. The use of ex-post data further complicates the situation as their variance from expected returns is normally high. These problems in measurement ultimately reduce the power of tests of the effects of liquidity on securities' pricing. There can be two possible

problems that face every test of liquidity with respect to asset pricing. 
i) Since a single measure cannot capture every aspect of liquidity, there will be an obvious bias in the result.

ii) There could be a large variance between ex-post and ex ante returns.

The list of liquidity measures is exhaustive; however, the following are the most widely used liquidity measures in empirical research.

\section{a) Bid-Ask Spread}

The bid-ask spread is normally calculated as the difference between the bid price by the bid-ask midpoint. This will directly calculate the cost of executing a small trade. There are two components of this spread. The first component compensates market-makers for inventory costs, order processing fees, and/or monopoly profits. This component is transitory since its effect on stock prices is unrelated to the underlying value of securities. The second component, an adverse selection component, arises because market-makers may trade with unidentified informed traders. To recover from losses to informed traders who might have better information, rational market-makers in a competitive environment widen the spread to recover profits from uninformed traders.

As a common measure of liquidity, the bid-ask spread has certain shortcomings. Hasbrouck (1991) points out that a tick size of $1 / 8$ limits the number of values the spread can take, thus price discreteness tends to obscure the effect of liquidity shocks in the cross section of firms. Moreover, Brennan and Subrahmanyam (1996) argue that the bid-ask spread is a noisy measure of liquidity because large trades tend to occur outside the spread while small trades tend to occur inside, which means that bid-ask quotes are only good for limited quantities.

\section{b) Stock Turnover}

Stock turnover is calculated as the ratio of trading volume to the number of shares outstanding. It is a trading activity measure that is often used as a proxy for liquidity. Amihud and Mendelson (1986) show that assets with higher spreads are allocated in equilibrium to portfolios with the same or longer expected holding periods. They argue that, in equilibrium, the observed market return must be an increasing function of the relative spread, implying that the observed asset returns must be an increasing function of expected holding periods. 
Given that turnover is the reciprocal of a representative investor's holding period and is negatively related to other liquidity costs such as bid-ask spreads, one can use it as a proxy for liquidity and the observed asset return must be a decreasing function of the turnover rate of that asset. Intuitively, in an intertemporal setting with zero transaction costs, investors will continuously rebalance their portfolios in response to changes in the investment opportunity set.

In the presence of transaction costs, such rebalancing will be performed more infrequently, resulting in reduced liquidity. However, Lee and Swaminathan (2000) question the interpretation of turnover as a proxy for liquidity because the relationship between turnover and expected returns depends on how stocks have performed in the past. More specifically, they find that high-volume stocks are generally glamour stocks and low-volume stocks are generally value or neglected stocks. Also, high-volume firms and low-volume firms differ significantly in terms of their past operating and price performance.

\section{c) Illiquid Ratio}

A natural measure of liquidity is a stock price's sensitivity to trades. Kyle (1985) postulates that, because market makers cannot distinguish between order flow generated by informed traders and by liquidity (noise) traders, they set prices as an increasing function of the order flow imbalance, which may indicate informed trading. This positive relation between price change and net order flow is commonly called the price impact. The illiquidity ratio of Amihud (2002), which is defined as absolute returns divided by the dollar trading volume, reflects the absolute (percentage) price change per dollar of trading volume and is a low-frequency analog to microstructure high-frequency liquidity measures. While the bid-ask spread captures the cost of executing a small trade, the illiquidity ratio, as a price impact proxy, captures the cost associated with larger trades. Furthermore, Hasbrouck (2003) shows that the Amihud (2002) illiquidity ratio is the best available price-impact proxy constructed from daily data.

\section{d) Return Reversal}

Pastor and Stambaugh (2003) develop a return-reversal measure as another form of price impact which reflects order-flow induced temporary price fluctuations. This measure is motivated by the Campbell, Grossman, and Wang (1993) model and its empirical findings. In a 
symmetric information setting, risk-averse market makers accommodate trades from liquidity or noninformational traders. In providing liquidity, market makers demand compensation in the form of a lower (higher) stock price and a higher expected stock return, when facing selling (buying) orders from liquidity traders. The larger liquidity-induced trades will result in greater compensation for market makers, causing higher volume-return reversals when current volume is high. This return reversal measure reflects only temporary price fluctuations arising from the inventory control effect of price impact.

\section{Empirical Evidence for Liquidity as a Determinant of Asset Returns}

The literature on the impact of liquidity on asset pricing is exhaustive, since the impact of liquidity can be observed on the returns on any possible financial asset. However, the focus of this literature review is on stocks and fixed income securities.

The impact of liquidity on asset pricing was first observed by Amihud and Mendelson (1986). They used stock returns for the period 1961-1980 and bid-ask spreads for 1960-1979. For each year, they grouped stocks into 49 portfolios based on the relative spreads and respective betas and further estimated monthly returns for each portfolio. The estimation model is a regression of the portfolio monthly return on estimated betas and average spreads. The regression explicitly accounted for the effect of spread on the portfolios' return and the slope of the return spread relationship. They concluded that the portfolio return increases with the bid-ask spread and the return spread slope decreases in the bid-ask spread. Thus, expected returns are an increasing function of illiquidity costs and the relationship is concave mainly due to the clientele effect.

Eleswarpu (1997) estimated a model where a stock return was regressed on the stock's beta, relative spread, and log (size). The estimation was based on Fama and MacBeth's (1973) methodology. The only consistently significant effect was that of relative spread, whose coefficient was positive and significant, whereas the coefficient of log (size) was negative and insignificant, while that of beta was positive and significant but not consistent.

Brennan et al. (1998) use the stock's trading volume as a measure of liquidity in a multifactor asset pricing model, a version of the APT, where the stock's excess return is a function of the loadings of the stock return on factors. They obtained risk-adjusted returns and regressed these 
returns cross sectionally on the stock's volume as well as other factors such as size, book-to-market ratio, price, dividend yield, and past returns. These factors were included to capture the momentum effect. The results demonstrated that volume has a negative and significant impact on riskadjusted stock returns.

Datar et al. (1998) used stock turnover as a measure of liquidity. They estimated the cross section of stock returns on stock turnover, controlling for size, book-to-market ratio, and beta. They observed that the cross section of stock returns was significant and negatively related to stock turnover. The turnover coefficient was also negative and significant. They concluded that lower liquidity (based on a longer holding period) of a stock resulted in higher expected returns.

All the above studies used historical returns to investigate the effects of liquidity on expected returns. Clearly, realized return is a very noisy measure of expected return. Loderer and Roth (2005) departed from this method and investigated how stock prices are affected by liquidity. Clearly, controlling for future cash flow growth and dividend payout, price is a measure of the expected return and, after controlling for risk, the results give the effect of liquidity on expected returns. Loderer and Roth used data from the Swiss Stock Exchange for the period 1995-2001 and regressed stock $\mathrm{P} / \mathrm{E}$, the price-earning ratio, on liquidity, measured by the relative bid-ask spread, after controlling for projected earnings growth obtained from analysts' reports, dividend payout ratio, risk, and size. The results show that the spread has a negative and significant effect on the cross section of stock prices.

Fixed income markets provide a fruitful area for examining the effects of liquidity on asset prices, since cash flows for fixed-income instruments are typically known with greater certainty than in the case of stocks. Studies of the effects of liquidity on bonds examine the effect of liquidity on the bond's yield to maturity, which-for riskless bonds, such as government securities-measures the expected return if the bond is held to maturity. For corporate bonds which can default, the yield to maturity after controlling for the effect of default provides a low-noise estimate of the expected return, compared to stocks where realized returns are used to estimate expected returns.

Warga (1992) studies holding period returns on constant duration portfolios of US Treasury notes and bonds, and measures the yield premium generated by liquidity differences in bonds. He constructs 
portfolios of off-the-run and on-the-run bonds using durations with narrow ranges and finds a consistent, positive, and significant yield differential between them of 55 basis points per annum.

Kamara (1994) studies the determinants of the yield differentials for matched-maturity note-bill pairs using 91 observations of bid and ask prices for treasury bills and notes with about 14 weeks to maturity over the period January 1977-July 1984. He posits that the note-bill yield differential reflects differences in liquidity, tax treatment, and dealer inventories. He proposes measuring the liquidity difference between notes and bills as the product of the volatility of the underlying rate by the ratio of the bills' turnover to the notes' turnover, where turnover is calculated using the ratio of dealer transactions to the absolute value of their net positions. Kamara finds that an average note-bill bid yields a differential of 34 basis points, a statistically and economically significant difference. The note-bill bid yield differential is found to increase in the liquidity risk, supporting the role of liquidity in the pricing of bonds.

Elton and Green (1998) examine the effect of liquidity on treasury securities, where liquidity is measured by the trading volume in the interdealer market. Controlling for the tax type of securities, they find significant differences between similar maturity bonds that differ in their trading volumes. The difference between the price of a low-volume bond and the weighted average of a pair of high-volume bonds with the same maturity but different coupons is negative and highly significant, meaning that the low-volume bond is cheaper and has a higher yield to maturity.

Krishnamurthi (2002) studies the price difference between the onthe-run and the most recent off-the-run 30-year bond. The price difference follows a systematic pattern over the auction cycle: It is highest right after the auction date and it declines to a small spread by the following auction date. To test whether the old bond-new bond yield difference results from a demand for liquid assets, Krishnamurthy regresses it on the yield spread between commercial paper and treasury bills (both for three months), which represent demand for liquidity since commercial paper is less liquid than bills. Studying all 30-year bond auctions in the 1990s, he finds that the yield difference increases when the yield spread between commercial paper and bills increases, and that the relation is stronger far from an auction date, when the liquidity demand is strongest. 


\section{Conclusion}

Traditional asset pricing models assume frictionless markets, thus ignoring the impact of market frictions on investors' required rate of return. In reality, investors, while making investment decisions, take into account the liquidity of that particular asset. The result is that all financial assets with same expected cash flows yield different market prices, thus making liquidity an important determinant of asset returns. However, like all other asset pricing variables (beta, etc.) the liquidity impact is not constant over time and, consequently, the pricing of liquidity (or illiquidity) risk varies.

The literature on the existence of the liquidity effect in determining asset returns is exhaustive and empirical evidence supports the presence of the liquidity effect. The empirical results show that both the level of liquidity and liquidity risk are priced. The concept of liquidity is broad and various methods have been deployed to measure its impact. The most widely used are bid-ask spread, stock turnover, and illiquid ratio. However, an inherent deficiency of empirics is that all aspects of liquidity cannot be captured by a single measure, so the results have a tendency to be biased. Moreover, the noise factor in the variance of ex post and ex ante returns further complicates the situation. Lastly, at times, the nonavailability of high-frequency data could be a possible constraint.

Despite estimation difficulties, it is well known that liquidity, estimated by any possible measure, has an impact on asset returns. A reduction in stock liquidity results in a reduction in stock prices and an increase in expected stock returns. Although we cannot discard traditional asset pricing models as a whole, their shortcomings should be addressed, including that of a frictionless market. The existence of the liquidity effect has solved many financial puzzles that were previously considered market anomalies. These include the small firm effect, the equity premium puzzle, and the risk-free rate puzzle. 


\section{References}

Amihud, Y., and Mendelson, H. (1986). Asset Pricing and the Bid-Ask Spread. Journal of Financial Economics, 17, 223-249.

Amihud, Y. (2002). Illiquidity and Stock Returns: Cross-Section and TimeSeries Effects. Journal of Financial Markets, 5(1), 31-56.

Bachelier, L. (1900). Theorie De La Speculation. Annales de l'Ecole Normale Superieure de Paris.

Banz, R. W. (1981). The Relationship between Return and Market Value of Common Stocks. Journal of Financial Economics, 9, 3-18.

Brennan, M.J., and Subrahmanyam, A. (1996). Market Microstructure and Asset Pricing: On the Compensation for Illiquidity in Stock Returns. Journal of Financial Economics, 41, 441-464.

Brennan, M.J., Chordia, T., and Subrahmanyam, A. (1998). Alternative Factor Specifications, Security Characteristics, and the Cross Section of Expected Stock Returns. Journal of Financial Economics, 49, 345-373.

Campbell, J. Y., Grossman, S. J., and Wang, J. (1993). Trading Volume and Serial Correlation in Stock Returns. Quarterly Journal of Economics, 108, 905-939.

Chordia, T., Roll, R., and Subrahmanyam A. (2002). Order Imbalance, Liquidity and Market Returns. Journal of Financial Economics, 65, 111-130.

Datar, V. T., Naik, N.Y., and Radcliffe, N. (1998). Liquidity and Stock Returns: An Alternative Test. Journal of Financial Markets, 1, 205-219.

Eleswarapu, V.R. (1997). Cost of Transacting and Expected Returns in the Nasdaq Market. Journal of Finance, 52, 2113-2127.

Elton, E. J., and Green, T.C. (1998). Tax and Liquidity Effects in Pricing of Government Bonds. Journal of Finance, 53, 1533-62.

Fama, E., and MacBeth, J. (1973). Risk, Return and Equilibrium: Empirical Tests. Journal of Political Economy, 81, 607-636. 
Fama, E., and French, K. (1992). The Cross Section of Expected Stock Returns. Journal of Finance, 47(2), 427.

Hansen, L.P., and Jagannathan, R. (1997). Assessing Specification Errors in Stochastic Discount Factor Models. Journal of Finance, 52, 557-590.

Hasbrouck, J. (1991). Measuring the Information Content of Stock Trades. Journal of Finance, 46, 179-207.

Hasbrouck, J. (2003). Intraday Price Formation in US Equity Index Markets. Journal of Finance, 58(6), 2375-2400.

Kamara, A. (1994). Liquidity, Taxes, and Short-Term Treasury Yields. Journal of Financial and Quantitative Analysis, 29, 403-416.

Keynes, J.M. (1930). Treatise on Money. London: Macmillan.

Krishnamurthi, A. (2002). The Bond/Old-Bond Spread. Journal of Financial Economics, 66, 463-506.

Kyle, A.S. (1985). Continuous Auctions and Insider Trading. Econometrica, $53,1315-1335$.

Lee, C.M.C., and Swaminathan, B. (2000). Price Momentum and Trading Volume. Journal of Finance, 55(5), 2017-2069.

Lintner, J. (1965). The Valuation of Risk Assets and the Selection of Risky Investments in Stock Portfolios and Capital Budgets. Review of Economics and Statistics, 47, 13-37.

Loderer, C., and Roth, L. (2005). The Pricing Discount for Limited Liquidity: Evidence from SWX Swiss Exchange and the Nasdaq. Journal of Empirical Finance, 12, 239-268.

Markowitz, H. (1952). Portfolio Selection. Journal of Finance, 77-91.

Mossin, J. (1966). Equilibrium in a Capital Asset Market. Econometrica, 34, 768-783.

Pastor, L., and Stambaugh, R. (2003). Liquidity Risk and Expected Stock Returns. Journal of Political Economy, 111, 642-685. 
Rosenberg, B., Reid, K., and Lanstein, R. (1985). Persuasive Evidence of Market Inefficiency. Journal of Portfolio Management, 11, 9-17.

Ross, S.A. (1976). The Arbitrage Theory of Capital Asset Pricing. Journal of Economic Theory, 13, 341-360.

Rouwenhorst, K.G. (1999). Local Return Factors and Turnover in Emerging Stock Markets. Journal of Finance, 54, 1439-1464.

Sharpe, W. (1964). Capital Asset Prices: A Theory of Market Equilibrium under Conditions of Risk. Journal of Finance, 425-442.

Tobin, J. (1958). Liquidity Preference as Behaviour towards Risk. Review of Economic Studies, 67.

Warga, A. (1992). Bond Returns, Liquidity, and Missing Data. Journal of Financial and Quantitative Analysis, 27, 605-617. 